\title{
Physician Usage of Technology and Opportunities for Continuous Care Management of Pediatric Asthma Patients
}

\author{
Adebola A. Osuntogun, Rosa I. Arriaga \\ School of Interactive Computing \\ Georgia Institute of Technology \\ Atlanta, GA 30332 \\ \{bola,arriaga\}@cc.gatech.edu
}

\begin{abstract}
This paper presents a qualitative study of the technology and communication means available for physicians in a metro-area pediatric pulmonary practice. We emphasize the design opportunities available for leveraging this technology to include continuous care and monitoring of pediatric asthma patients. These include building a web based system that focuses on communication between the caregiver and the physician, alerting physicians via email of positive responses by the parent to high interest questions and allowing for merging this system with the Electronic Medical Records (EMR) system.
\end{abstract}

Keywords-pediatric asthma; technology; healthcare; qualitative study

\section{INTRODUCTION}

Asthma is a disease of the lungs that makes breathing difficult. It is most common among children but also extends into adulthood. The main symptoms include wheezing, breathlessness, chest tightness and coughing. Asthma is triggered by various factors including environmental conditions, strenuous physical exercise, high humidity, dust, pollen, outdoor air pollution and pets. Asthma is a very heterogeneous disease with attacks being triggered by different factors for each individual. It is difficult to diagnose in children 5 years of age and younger but a spirometry(lung function test) can be used to measure airflow and diagnose asthma[1].

Asthma is one of the most common chronic childhood conditions in the United States and is a major cause of disability. It affects a child's life by limiting the ability to play, learn and sleep which results in missed school days for the child and missed work days for the parents. It also leads to expensive interventions which amount to increased medical costs through hospitalizations and emergency department visits.

As of 2007, 9.1\% (6.7 million) children in the United States had asthma. There is a higher prevalence among older children (11-17 years) but use of health care is highest among younger children (0-4years of age) [2]. One in eleven children is reported to have asthma but there are racial disparities. In comparison with White children, children of American Indian and Alaskan descent are 1.3 times more likely and Black children are 1.6 times more likely to have current asthma with Asian children having the lowest prevalence [2]. Racial disparities also exist in Emergency Department visits, hospitalizations and death.

Due to the high prevalence of pediatric asthma, the Centers for Disease Control and Prevention(CDC) has major goals of improving the tracking of asthma symptom severity and control, measurement of asthma burden in local communities, support and evaluation of interventions and treatment programs, dissemination of interventions that are proven effective for reducing symptoms and adverse outcomes. Major aspects of asthma prevalence that are monitored include ambulatory care visit rates, emergency department visit rates, hospitalization rates and death rates.

The use of technological solutions for the continuous care and management of patients with chronic diseases are rapidly increasing. There are a growing number of studies on the patients' use of technology for asthma care and its effect on their disease management [3-6], but the physician perspective has received less attention [7,8]. This is an important gap because it is understood that the best management strategies for chronic care are ones where the physician and patient are in lock step with their goals [9]. There is also a burgeoning awareness that the best management occurs when technology for pediatric patients takes an ecological approach and engages the various stakeholders that interact with the child on a continuous basis [10].

Specifically, little is known about the role that physician awareness about patient's symptoms between scheduled medical visits has on their management strategies. Scheduled visits are one of the main management strategies for children that have moderate to severe asthma. These occur about 2 to 4 times a year. Yet the physician is unaware of the child's asthma status between visits unless the child has an emergency room visit or is hospitalized.

In this study we focus on exploring the physicians' use of technology and opportunities for leveraging this use for the continuous care of pediatric asthma patients. To achieve this goal, a qualitative study was conducted to explore technology availability and usage in a pediatric pulmonary clinic. Five 
physicians were shadowed and then interviewed to determine their needs with regards to monitoring patients remotely. The study findings suggest that there is a major use of technology in the form of Electronic Medical Records (EMR) and Blackberries for communication at the clinic.

Based on this data we deduced design implications for what we call a "physician dashboard". These findings indicate that the system should be geared toward the physician and caregiver (rather than the patient), it should also include alerts to the physicians and perhaps be merged with the pre-existing EMR system.

\section{RELATED WORK}

The earliest work documenting the use of electronic communication between physicians and patients was accomplished by Adams et al [11]. In their study, they implemented a method for direct email communication between patients and physicians in a Dutch eye hospital. They deemed their study unsuccessful due to the infrequent use of the system. Analysis of the usage pattern indicated that there were several presumptions about the technology and how it would be used by patients. The failure of this study underscores the need to use qualitative research methods to understand the intended users and usage of a system prior to deployment, hence the rationale behind our initial observation of physicians.

Several studies have focused on the use of communication technologies to increase patient and physician communication and monitoring of asthma status. The prevalent technologies include web-based, internet diaries or e-mail communication $[3,4,12,13]$ and Short Message Service (text messaging) or mobile phone usage $[5,6,14,15]$. These communication methods are also used in connection with devices built for asthma monitoring from the home $[16,17]$.

The studies cited above emphasize the development of the technology and corresponding performance and outcomes with regards to usage. Our qualitative study differs from these studies in that we perform an analysis of the technology already available in the physicians' environment and use that as a basis for design with the possibility of leveraging such technology for management of pediatric patients' asthma.

\section{METHOD}

Observations were conducted at a pediatric pulmonary clinic in a large metro area. The main focus was on the technologies being used including the method of usage and length of usage. A total of five physicians were observed and interviewed to understand their greatest needs in relation to monitoring pediatric asthma patients. A paper based preliminary design concept of a Short Message System (SMS) and web based physician portal to view patient information was shown to the physicians to engage them in discussions about the possibilities and usefulness of such a system (See Fig.1).The system is designed for asthma management and continuous care in between visits to the clinic.

Each physician was shadowed for approximately 3 hours. Questions were asked during the observation process to better understand the physicians' workflow. After the observation, physicians were interviewed for about 30 minutes to obtain information regarding their usage of computers, mobile phones and other communication technology noted during the observation.

Physicians were acquainted with the concept of the SMS based information gathering method for patients to use between regularly scheduled medical visits [18], see Table II pre-observation). Using this system, patients will be sent questions based on a standardized questionnaire about asthma symptoms and medication usage. The pediatric/adolescent (517 years old) Asthma Therapy Assessment Questionnaire (ATAQ) is a validated parent completed tool which indicates areas of potential asthma care problems in symptom control, behavior and attitude barriers, self-efficacy barriers and communication gaps with physicians [19]. These questions would be sent on a regular basis (every other day). Responses to the questions will be made available for physician viewing on a web-based dashboard. Physicians were shown paper prototypes of the dashboard and asked to comment on the format, display and type of information that was presented.

\section{PAPER PROTOTYPE}

To stimulate understanding of the new technology we were proposing, paper prototypes with mock screens were shown to the physicians. The prototypes consisted of a login screen, dashboard view, patient list view and detailed patient information view which are shown in Figure 1. During the interview portion of the data collection process, the prototypes served as a method for conveying our ideas and kindling new ideas from the physicians' perspective.
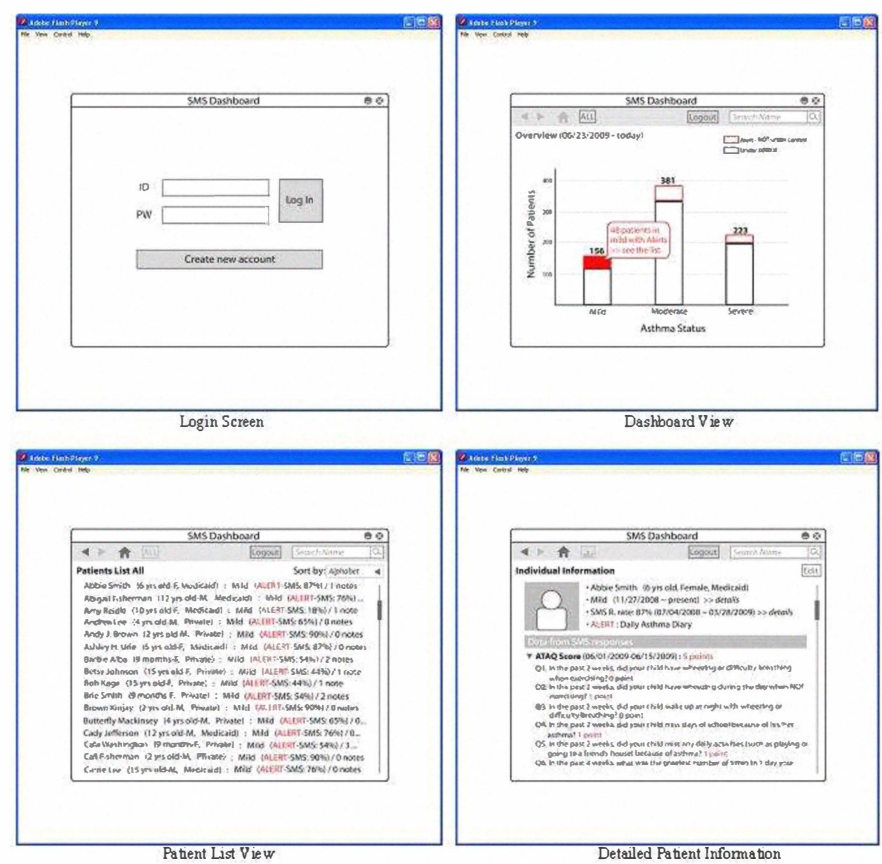

Figure 1. Paper Prototype of the Physician Dashboard 


\section{DATA ANALYSIS}

Analysis of the raw qualitative data was accomplished by tabulating observation notes and responses to survey questions from each physician observation. Observations were grouped into cohesive topics from which counts of physician responses and observations of each topic were used to compute quantitative scores. These scores are used for analysis and display purposes to provide an overall view and understanding of the technology usage pattern of the physicians in the pediatric pulmonary center.

\section{FINDINGS}

The major findings from the observation and interview process are described in this section.

\section{A. Technology Availability and Usage}

The technologies used by the physicians included laptops or small digital notebooks, mobile phones, pagers and the light alert system. Table I shows the Likert scale scoring guide used to quantify the data collected during the observation and interviews. The laptops or digital notebooks were connected to the internal network and linked to the clinics EMR system. Fig. 2 shows that all physicians used the laptop mostly to view or type notes into the EMR system. The EMR system was also used for alerting physicians of patient arrivals and stage in the clinical visit hence, physicians were constantly monitoring the system to determine if and when a patient was accessible. All the physicians had Blackberries but their usage patterns differed as shown in Fig. 3. Email and text messages were most often viewed on the Blackberry.

TABLE I. LIKERT SCALE SCORE

\begin{tabular}{|ll|}
\hline Likert Scale & Score \\
Never & 0 \\
Once or Twice & 1 \\
Often & 2 \\
Always & 3 \\
\hline
\end{tabular}

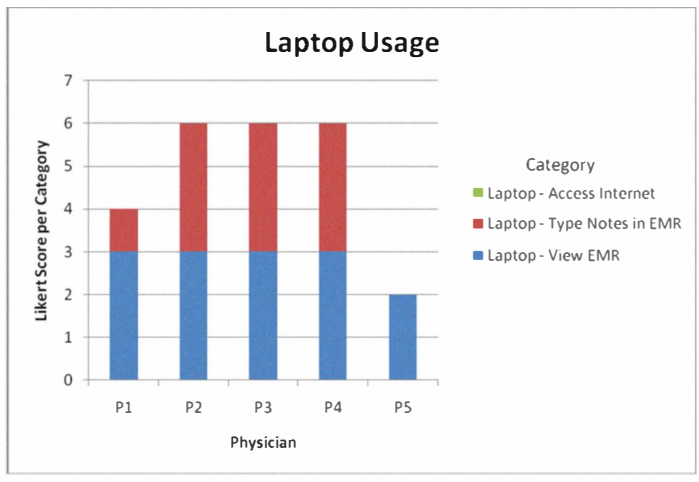

Figure 2. Physician laptop usage.

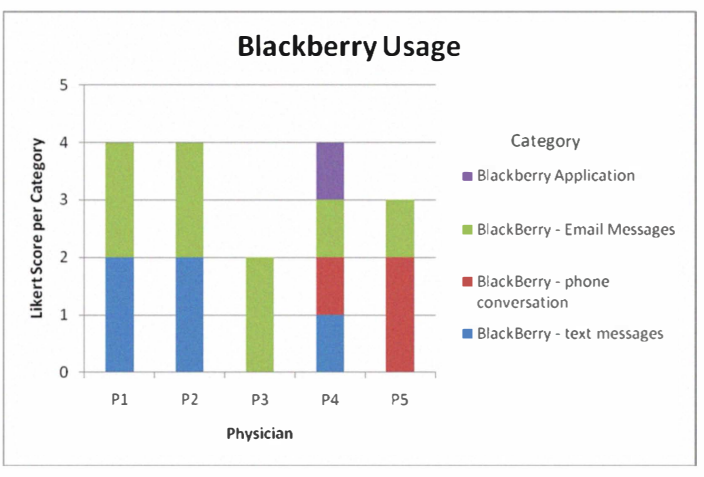

Figure 3. Physician Blackberry usage

In addition to the standard technologies, this clinic also utilized a "light alert system" that consists of a series of multicolored lights that blink based on the location or requests for the respiratory therapist, physician or nurse. There is a centralized control area in the clinic in which all the lights are arranged. A physician can press the light button from an examination room to summon a nurse. This occurred several times during the observation of physician 3 , who requested printed prescriptions from the nurse by pressing the light. The light alert system is also connected to the physicians office such that when a physician is needed the light blinks.

\section{B. Information Monitoring}

During the observation period, physicians were often monitoring different events and tasks using their laptop or Blackberry. Fig. 4 shows the self-reported data from physician interviews indicating which information was being monitored constantly. During the work hours all physicians have access to computers with internet connection with which they monitor patient arrival and status while Blackberries are used to monitor emails. During the interviewing process, physicians were asked which information they would like to be alerted about with regards to patients asthma status. Fig. 5 indicates that their main concern centers around the use of rescue medication. This is medication that is taken for quick relief of symptoms once they start; as opposed to daily medication that controls asthma.This is because inappropriate use of rescue medication is correlated with morbidity. Thus a patient who uses their rescue medication too frequently has poorly controlled asthma and needs to see the physician.

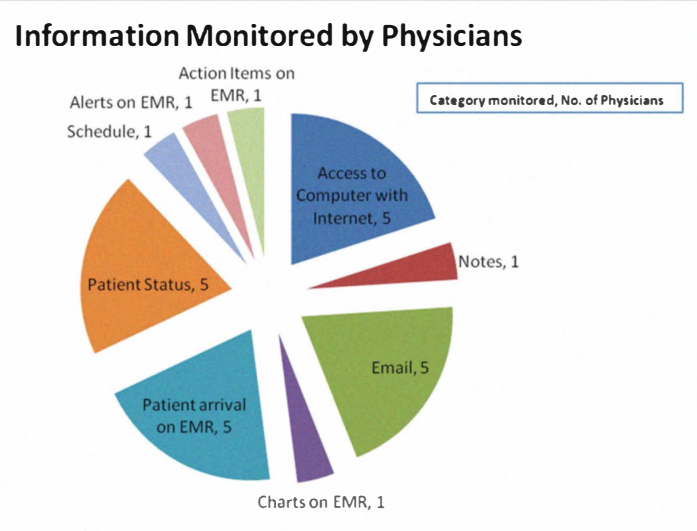


Figure 4. Information monitored by physicians

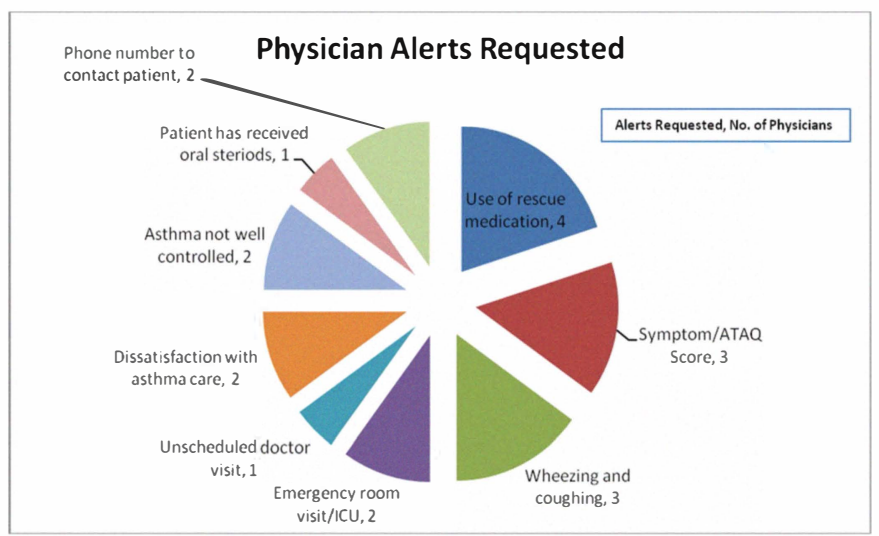

Figure 5. Physician alerts requested

\section{Physician Interactions}

During the observation period physicians interacted with clinic staff, patients and parents of the patients. Interactions with clinic staff included receiving text messages or email from the front desk personnel about patients being late, conversations with nurses in the hallway or communication using the light alert system. The EMR system was also used to leave notes for physicians. Fig. 6 shows the number of patients seen by each physician; patient ages ranged from 3 to 16 years of age. For the younger children most of the asthma status questions were directed to the parents, while for the older patients the physician asked questions directly.

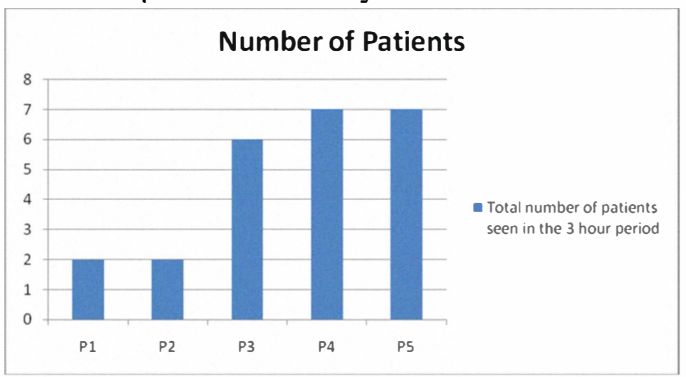

Figure 6. Total number of patients seen by each physician within the three hour observation period.

\section{DISCUSSION}

Pediatric asthma has reached alarming rates in the US [2]. In current practice the physician only comes in contact with the pediatric patient during a scheduled visit which may only be a couple of times a year or if an emergency situation arises. The goal of this study was to understand what the current technology usage is for pediatric pulmonologists such that a web based solution could be modified to provide continuous care to the patients. And thus physicians can intervene when serious breaches to their asthma management plan occurs (e.g., misuse of rescue medication). We addressed this goal by doing a qualitative assessment of what the current technological affordances were of a pediatric pulmonology practice. We studied the practices of a set of physicians from a large metro area pediatric pulmonary clinic. Four themes emerged that can be used to design technology for monitoring of pediatric asthma patients.

The main themes emerging from the qualitative studies are summarized in Table II and clarified below. Physician responses/observations indicate the new information gained by conducting the observation and summarizing the data.

TABLE II. DESIGN IMPLICATIONS

\begin{tabular}{|c|c|c|c|}
\hline Features & Interview Questions & $\begin{array}{l}\text { Physician } \\
\text { Responses/Observations }\end{array}$ & Design Implications \\
\hline \multirow[t]{3}{*}{ Alert System } & $\begin{array}{l}\text { What type of alerts } \\
\text { would you want to } \\
\text { receive about patients? }\end{array}$ & $\begin{array}{l}\text { Over-use of rescue } \\
\text { medication (Albuterol) } \\
\text { ATAQ Symptom Score } \\
\text { Emergency Room Visits }\end{array}$ & \multirow{3}{*}{$\begin{array}{l}\text { Program system to } \\
\text { send alerts addressing } \\
\text { specific concerns to } \\
\text { physicians via email } \\
\text { in the morning. }\end{array}$} \\
\hline & $\begin{array}{l}\text { What format would } \\
\text { you prefer to receive } \\
\text { alerts? }\end{array}$ & Email Messages & \\
\hline & $\begin{array}{l}\text { At what time during } \\
\text { the day would you } \\
\text { prefer to receive } \\
\text { alerts? }\end{array}$ & $\begin{array}{l}\text { During business hours } \\
\text { especially early in the } \\
\text { morning }\end{array}$ & \\
\hline Communication & $\begin{array}{l}\text { What do you typically } \\
\text { tell patients about } \\
\text { keeping you informed } \\
\text { of their asthma status? }\end{array}$ & $\begin{array}{l}\text { Caregivers are asked to } \\
\text { call the physicians' office } \\
\text { if they have any problems }\end{array}$ & $\begin{array}{l}\text { Provide a method for } \\
\text { initiating calls from } \\
\text { the dashboard if there } \\
\text { is an alert }\end{array}$ \\
\hline $\begin{array}{l}\text { Reflection on } \\
\text { Patient Status }\end{array}$ & $\begin{array}{l}\text { Do you have a method } \\
\text { of reflecting on how } \\
\text { asthma patients are } \\
\text { doing prior to arrival } \\
\text { at the clinic? }\end{array}$ & $\begin{array}{l}\text { No current method } \\
\text { except checking to see if } \\
\text { there are changes in their } \\
\text { records for instance } \\
\text { phone calls to the clinic } \\
\text { or hospitalizations, using } \\
\text { the EMR system. }\end{array}$ & $\begin{array}{l}\text { Physician dashboard } \\
\text { can provide status for } \\
\text { all patients. This } \\
\text { information can also } \\
\text { be added to the EMR }\end{array}$ \\
\hline \multirow[t]{2}{*}{$\begin{array}{l}\text { Leveraging } \\
\text { Existing } \\
\text { Technology }\end{array}$} & $\begin{array}{l}\text { Do you have access to } \\
\text { a computer with } \\
\text { internet service? }\end{array}$ & $\begin{array}{l}\text { Yes } \\
\text { Physicians have laptops } \\
\text { and Blackberries with } \\
\text { internet connection }\end{array}$ & $\begin{array}{l}\text { Use of available } \\
\text { internet access via } \\
\text { laptops or } \\
\text { Blackberries for } \\
\text { physician dashboard }\end{array}$ \\
\hline & & $\begin{array}{l}\text { Physicians are constantly } \\
\text { using the EMR system }\end{array}$ & $\begin{array}{l}\text { Connection of SMS } \\
\text { responses to existing } \\
\text { patient record in } \\
\text { EMR }\end{array}$ \\
\hline
\end{tabular}

\section{Introduction of Alert Systems for Physicians}

Based on the interviews with physicians, there is currently no method of being informed between visits of a patients' asthma status. Patients may have serious asthma attacks between clinic visits of which their pulmonologist is informed only during their scheduled visits. Physicians would like a method of monitoring patients which alerts them of any conditions that may indicate signs of asthma status deterioration or other dire conditions. If physicians are alerted of possible situations, they can take necessary actions to ensure that the patients' status is not exacerbated hence reducing the rate of Intensive Care Unit (ICU) and Emergency Room visits. Before this study we had envisioned that the ATAQ questionnaire could provide a general alert of the patient's asthma management status (green (no symptoms), yellow (some symptoms) or red (many symptoms). Physicians stated that they would also like to be alerted if a patient responded positively to questions regarding frequent use of asthma rescue medication, health resource utilizations for instance emergency room visits or, hospital stay.

Physician: "I would need a prompt talking about each morning, an alert email. Email me for a new alert... And then a once a week email saying something like your asthma data is updated wouldn't you love to look at it. I guess once a week 


\section{Physician/Clinic Communication with Patients}

At present, most communication with patients is patient caregiver (parent) initiated. Phone calls from the clinic are often to report laboratory test results and to call caregivers back. It is only high risk patients that are monitored by the clinic with phone calls and checking that medication prescriptions are filled. The creation of a system which alerts the physicians of possible problems with patients is new. This system (e.g., the dashboard) will initiate calls from the clinic to caregivers to ensure that all is well or suggest an earlier visit to the pulmonologist than was previously scheduled. This is an important improvement since asthma-related-morbidity is not correlated with symptom status; that is children with moderate asthma are just as likely to succumb to asthma related deaths than are children with severe asthma.

Physician: "Well, I usually say, call us if you need us and I ask them if they still have my card, has my cell phone number on it and the asthma management plans that they have all our telephone number on it, so we encourage them to contact us by telephone, we do not encourage them to email us."

\section{Opportunities for reflection on overall patient status}

A system with current information about a patients' asthma status will provide a method for a pulmonologist to reflect on the patients' history prior to scheduled visits. This will ensure that physicians are well informed and thus better able to treat a patients' condition. It can also provide 'talking points' to address during the scheduled visit. For example if the patient's parent is reporting that the child's asthma is interfering with the child's ability to play then the physician can address this during the visit.

Physician: "if I had a good reason to, I would [go on the internet]... like to look up your asthma control data. Like I'm in the room with an asthmatic and he's telling me he's doing great. I'd say let me look up your scores to see if you said that every day."

\section{Leveraging Existing Technology}

It is interesting to note that the technological infrastructure that is needed for continuous management of pediatric asthma patients is available in this clinic. For instance the EMR system is already in place and frequently used by all physicians; data about patients' asthma status and different alerts can be linked to the EMR system thus eliminating the need to implement a new system for continuous care. The web based solution however would benefit physicians that do not have sophisticated technological support.

Physician: "Well first of, I'd like something that is integrated into my electronic medical records so that those data can then be pulled in easily to the EMR if that's possible, that way when I'm pulling up a patients' chart then I can look to see how have they been controlled over the past month and since their last visit."

\section{CONCLUSION}

Observations and interviews conducted at the pediatric pulmonary clinic kindled design suggestions that differed from the original paper prototype. These findings indicate that the system should alert physicians via email of positive responses to specific questions by the parent, communication should be between physicians and caregivers/parents as indicated by the current workflow. Also, significant usage of the EMR system suggests merging of continuous care information with the existing system. Overall, exploration of the technology available and frequency of usage in this pediatric asthma management clinic illustrates the potential for improving asthma care by leveraging available technology to support physician monitoring of patients.

\section{ACKNOWLEDGEMENTS}

We would like to thank our collaborators at Georgia Pediatric Pulmonology Associates (GPPA) and acknowledge the suggestions and contributions of Prof. Gregory D. Abowd and Hee Young Jeong.

\section{REFERENCES}

[1] "Centers for Disease Control and Prevention: Asthma." http://www.cdc.gov/asthma.

[2] L.J. Akinbami, J.E. Moorman, P.L. Garbe, and E.J. Sondik, "Status of Childhood Asthma in the United States, 1980-2007," Pediatrics, vol. 123, 2009, p. S131.

[3] L.M. Rasmussen, K. Phanareth, H. Nolte, and V. Backer, "Internetbased monitoring of asthma: a long-term, randomized clinical study of 300 asthmatic subjects," The Journal of allergy and clinical immunology, vol. 115, 2005, pp. 1137-1142.

[4] J. Finkelstein, M.R. Cabrera, and G. Hripcsak, Internet-Based Home Asthma Telemonitoring* Can Patients Handle the Technology?, Am Coll Chest Phys, 2000.

[5] J. Anhloj and C. Mloldrup, "Feasibility of collecting diary data from asthma patients through mobile phones and SMS (short message service): response rate analysis and focus group evaluation from a pilot study," Journal of Medical Internet Research, vol. 6, 2004.

[6] D. Ryan, W. Cobern, J. Wheeler, D. Price, and L. Tarassenko, "Mobile phone technology in the management of asthma," Journal of telemedicine and telecare, vol. 11, 2005, pp. 43-46.

[7] H. Pinnock, R. Slack, C. Pagliari, D. Price, and A. Sheikh, "Professional and patient attitudes to using mobile phone technology to monitor asthma: questionnaire survey," Primary Care Respiratory Journal, vol. 15, 2006, pp. 237-245.

[8] E.M. Liederman and C.S. Morefield, Web messaging: a new tool for patient-physician communication, Am Med Inform Assoc, 2003.

[9] N.M. Clark, M. Gong, and N. Kaciroti, "A model of self-regulation for control of chronic disease," Health Education \& Behavior, vol. 28, 2001, p. 769.

[10] H.Y. Jeong and R.I. Arriaga, "Using an ecological framework to design mobile technologies for pediatric asthma management," Proceedings of the 11th International Conference on HumanComputer Interaction with Mobile Devices and Services, 2009, p. 17.

[11] S. Adams, R. Bal, and J. De Jong, "Full of promise, failed in practice: a discussion of barriers encountered during an attempt to integrate physician-patient e-mail communication in the care process at a Dutch Eye Hospital," International Journal of Healthcare Technology and Management, vol. 7, 2006, pp. 252-265.

[12] R.L. Jan, J.Y. Wang, M.C. Huang, S.M. Tseng, H.J. Su, and L.F. Liu, "An internet-based interactive telemonitoring system for improving childhood asthma outcomes in Taiwan," Telemedicine and e-Health, vol. 13, 2007, pp. 257-268.

[13] M. Glykas and P. Chytas, "Technological innovations in asthma patient monitoring and care," Expert Systems with Applications, vol. 27, 2004, pp. 121-131. 
[14] H. Pinnock, R. Slack, C. Pagliari, D. Price, and A. Sheikh, "Understanding the potential role of mobile phone-based monitoring on asthma self-management: qualitative study," Clinical and Experimental Allergy, vol. 37, 2007, pp. 794-802.

[15] H.R. Lee, S.K. Yoo, S.M. Jung, N.Y. Kwon, and C.S. Hong, "A Webbased mobile asthma management system," Journal of telemedicine and telecare, vol. 11,2005 , pp. 56-58.

[16] D. Willems, M.A. Joore, J.J. Hendriks, R.A. van Duurling, E.F. Wouters, and J.L. Severens, "Process evaluation of a nurse-led telemonitoring programme for patients with asthma," Journal of Telemedicine and Telecare, vol. 13, 2007, p. 310.
[17] J. Finkelstein, G. O Connor, and R.H. Friedman, "Development and implementation of the home asthma telemonitoring (HAT) system to facilitate asthma self-care," Studies in health technology and informatics, 2001, pp. 810-814.

[18] T. Yun, H.Y. Jeong, R.I. Arriaga, and G.D. Abowd, "Daily Talks: Short Message Service for Pediatric Asthma Management," 2009.

[19] E.A. Skinner, G.B. Diette, P.J. Algatt-Bergstrom, T.T. Nguyen, R.D. Clark, L.E. Markson, and A.W. Wu, "The asthma therapy assessment questionnaire (ATAQ) for children and adolescents," Disease Management, vol. 7, 2004, pp. 305-313. 